SHS Web of Conferences 6, 02002 (2014)

DOI: $10.1051 /$ shsconf / 20140602002

(C) Owned by the authors, published by EDP Sciences, 2014

\title{
Farmer Education Development under the Perspective of Migrant Workers' Intergenerational Mobility
}

\author{
Fan Rong ${ }^{\mathrm{a}}$ \\ College of Humanities and Law, Northwestern Polytechnical University, 710072 Xi'an, China
}

\begin{abstract}
This paper argues the appearances of at least three generations' replacement of migrant workers since the reform and open policy, which is the first generation, the new generation and the third generation. Under the condition of disparate family and social circumstances, the migrant workers are no longer the abstract groups with the same degree of homogeneity. The public tendency is more clearly in the aspect of mobility motivations, city identity and self-identity, employment industry, education and skills training. Therefore, the importance of migrant workers education highlights increasingly. According to the analysis of social development and migrant workers' self-development, we need to develop farmer education. But the present situation of farmer education is misfit. So we need to put forward the countermeasures and suggestions on peasants' compulsory education, vocational training institutions, and amateur cultural education.
\end{abstract}

Keywords. migrant workers; intergenerational mobility; farmer education

\section{The migrant workers' intergenerational division}

With the rapid development of China's economy and society, there are significantly different individual personality characteristics between the younger generation migrant workers and the older generation ones. The academic mainstream point of view is that it is divided of the migrant workers into "first generation" and "the second generation or new generation". The ones who were born before 1980 were considered as the first generation migrant workers, they began to flow from the agricultural and rural situation into the migrant situation in the city in the 1980s and 1990s. The new generation migrant workers were those people who were born after 1980s (at the age of 16 years old to 30 years old), their registered permanent residence is in the countryside, but they have been coming to work in the city in 1990s. Because they were not born and grew up in the process of the old generation's out migrantion for work, they were transitional migrant workers between the old generation and the next generation. With the development of times and society, there is a further differentiation trend in the new generation migrant workers' groups. These new changes are not clearly observed with a general "new generation" concept, which is not conducive to our targeted, level understanding of the new problems and new demand of migrant workers. The new generation migrant workers are people who are currently residing in the main city, because they wish they can stay long in the inflow, and have a tendency to move with all their family, many of them bring their children to the city. Some scholars call these children as "new nature migrant workers". The new nature migrant workers are the ones who are born and grow up in the city, can't be engaged in farm work, have little contact with rural

\footnotetext{
a Corresponding author: fanrong313@126.com
}

This is an Open Access article distributed under the terms of the Creative Commons Attribution License 2.0, which permits unrestricted use, distribution, and reproduction in any medium, provided the original work is properly cited. 
area. Their registered permanent residence is not in the city whey are living, but their identity is peasant and they have a part of responsible fields in the countryside. This group includes minor children, adolescents (following their parents who live in the city), adults (studying in the city and working there after graduation) [1].

In the previous research results, this paper considers that it shows the obvious stage and imbalance according to the development of migrant workers' experience after 30 years of Reform and Openingup. There are obvious intergenerational differences in the migrant workers' social experience and ideology in the different stages. Therefore, there are at least three generations occurred in reality, i.e. the first generation the new generation and the third generation. The third generation migrant workers are the ones who join in the migrant workers team after 2001, which consist of the new nature migrant workers and the future migrant workers (adults, teenagers and children left in the rural areas). In conclusion, it can be divided into the flowing generation and the left-behind generation. According to relevant statistics, there are 58 million rural left-behind children aged 0-14 in our country, 44 million flowing children, and the total scale of the rural children is about 130 million. Obviously, when these children continuously take part in the migrant worker group, the new generation migrant workers will show new features. Because the flowing generation in the social experience is getting far away from the agriculture, the rural and the farmers gradually, their pattern of livelihood, education, social interaction, cultural entertainment, consumption habits, and even the clothes, accents are increasingly showing citizenization, while the left-behind generation children are growing in the countryside, they are lack of parental love, represented in terms of family, education and work in social experience, they will show their own characteristics. Although this concept has not been unanimous recognition, but the emergence of this group is inevitable. There should be a strategic vision in the current study of migrant workers, we should pay more attention to the study of the third generation of migrant workers, especially the problem of the left-behind children, which will be related to the future of Chinese agriculture.

\section{Generational comparison and evolution trend of migrant workers}

Because the growth environment and the education environment in the three generations is different, this will largely determine that there will be have an obvious difference in their culture, concept and behavior.

\subsection{A change of flowing causes}

Moving to work in the city for the migrant workers is based on a "push-pull effect"[2], this applies to all types of migrant workers, but what kind of factors are in the "push" and "pull", they are total different in the two generations of migrant workers, the wealth of push-pull effect is prominent on the first generation of migrant workers, working in the city becomes their best choice to change the poor state. However, the new generation migrant workers is different, their motive to enter to the city is for personal development, the economic factor turns into the secondary factor, the city life is a great attraction to them. The reason for the third generation migrant workers working in the city shows a diversified tendency, considered of the growth experience of the flowing generation, the third generation of migrant workers and their urban peers is more alike. They went downtown lack of subjective decisive, the work motivation is not inclined to force by life, but more accustomed to urban life, they thought that staying in the city is a natural thing; And young people of the new migrant workers on the purpose of employment is more than just graduated, to exercise themselves, go to play only, learn a technology, boring at home. The country push is stronger.

\subsection{A city's identity gradually increases and leads to identity confusion}

Many of the new generation of migrant workers have gone into the city and the factory since they graduated from junior high school. Some still followed the working parents grew up in the city. Urban 
living and working experience make them on a city's identity degree higher than the first generation of migrant workers. The extent of social recognition for his hometown is in decline. Despite the current state of life in the city have not reached the degree of their satisfaction, most of them still don't want to return to rural areas. Strongly stimulating the urban culture, especially urban consumer culture, tends to make them like the city life in pursuit of higher material and spiritual enjoyment, prefer to stay in the city life. For the third generation of migrant workers, they have become accustomed to everything of the city, identity exists significant differences compared with the new generation. To be specific, the new generation mi-grant workers of $20.60 \%$ think that they belong to farmers, of which, the third generation of migrant workers think they are farmers proportion was only about $15.29 \%$, flow generation thinks he is the proportion of the farmers is lower, just $12.35 \% ; 27.69 \%$ of the new generation migrant workers think they belong to the "other" identity or couldn't say for sure belong to their own identity, this vague identity is more apparent in the third generation of migrant workers, accounted for $32.03 \%$, especially in the current generation ratio reached $44.44 \%$ [3]. It is thus clear that, the identity of the third generation of migrant workers, especially the flow generation even more vague even hesitant, they don't tend to identify themselves as more farmers, but also have to admit the reality of the citizens, there is more confusion in identification.

\subsection{More varied employment}

From various social survey statistical data as you can see the new generation of migrant workers the choice of one, two, three industry distribution for: select the first industry people is least, the second industry is in the middle, and the third industry is to choose the largest number of an industry. Because most of them were actually from migrant workers after leaving school, rarely to agricultural labor, do not have the basic experience and skills of agricultural production, agricultural production will be difficult to do. Industry as the second industry, mainly high-end industry knowledge intensive and technology-intensive enterprises, their demand for talent is compound talents with innovative consciousness and innovative ability, in new generation migrant workers, analysis of the current education situation, the man who can reach this level is few and far between. Labor-intensive industry mainly relies on a large number of cheap labor to create value, profit is not high, the strength is not strong, fight risk ability is poor, and is vulnerable to all sorts of fluctuations, new generation of migrant workers in these industries is difficult to find a lasting, stable and has development space work. The third industry to degree level, new generation of migrant workers by education degree is appropriate, for experienced specialized vocational training the new generation of migrant workers is likely to be more interested in. In a word, the tertiary industry will attract a new generation of migrant workers is the largest number of a business, also will be the third generation of migrant workers obtain employment of major industry. The third generation relative to the freshmen of migrant workers, migrant workers are more likely to obtain employment in state-owned, collective, corporations, individuals and other properties of the enterprise.

\subsection{Level of education and vocational skills training level enhances unceasingly}

New generation of migrant workers with the conditions and degree of education have greatly improved, more education opportunities, at the same time have a strong desire to develop themselves, pay more attention to skill training and self-improvement. New generation migrant workers cultural level is still low, junior high school and above are the main, accounted for $90.4 \%, 0.71 \%$ which has not been to school, $8.88 \%$ of primary school, $65.19 \%$ of junior middle school, $19.88 \%$ high school and technical secondary school, $3.73 \%$ of college degree, $1.51 \%$ of undergraduate course, bachelor degree or above $0.1 \%[4]$. While the first generation of migrant workers cultural degree is given priority to with the junior middle school culture, but the proportion of junior high school graduates in the new generation migrant workers significantly higher than the first generation, $17.6 \%$ higher than that of, On the high school level of education, new generation of migrant workers is higher than the first generation of migrant workers by $5.2 \%$, average education duration of 9.37 years, 1.12 years higher 
than the first generation of migrant workers. Two phase contrast, new generation of migrant workers by education level has improved significantly. At the same time the new generation of migrant workers in professional trained staff ratio reached $36.9 \%, 14 \%$ higher than traditional migrant workers[5]. It is thus clear that, whether in the basic education stage or during the training, continuing education, new generation migrant workers have more advantages, show more strongly willingness, they hope to enrich and improve themselves, to gain more development opportunities, to realize their ideals in the city.

As the national policy tilt to the new generation of migrant workers, the children of the new generation of migrant workers by the proportion of higher academic education will rise, the whole quality of the third generation of migrant workers will gradually improve, and its slowly with urban residents stand on the same starting line, may create more. <2011China's migrant workers survey monitoring report> of the National Bureau of Statistics data show, migrant workers are mainly junior high school education, relatively high educational level of young migrant workers and migrant workers, illiteracy accounted for $1.5 \%$, primary school education accounted for $14.4 \%, 61.1 \%$ junior high school education, high school education accounted for $13.2 \%$, secondary and higher education accounted for $9.8 \%$, accounted for $93.8 \%$ of young migrant workers in the junior high school and higher education. The highest level of education of young migrant workers, is the most promising group of migrant workers. But the survey found that they generally expects to own better development, although have goals, but the goal is very fuzzy, not specific; generally know learning is very important to achieve the goal, but no specific learning plan.

From the performance of these intergenerational differences, in the final analysis urbanization tendency is very clear, this all depends on education, therefore, the importance of education for farmers has become increasingly prominent.

\section{Intergenerational mobility of migrant workers education demand analysis}

Migrant workers is the product of the process of the transfer of rural surplus labor, through the first generation of migrant workers, the new generation to third generation mobile, essentially through certain means and channels to change farmers' identity, the process of converting farmers occupation, overall showed a trend of upward mobility, the role of education cannot be discounted, farmer education throughout the whole process. This article focuses on the third generation of migrant workers flow generation and staying generation to achieve upward mobility, or into the city, or become new farmers engaged in modern agriculture, all have demand for farmers' education.

\subsection{Migrant workers need to achieve intergenerational upward mobility with new qualities and abilities}

Human capital impact important variables of migrant workers into urban society, its role cannot be ignored. But through the study found that in the influence of migrant workers social integration variables, affected by the fixed number of year of the education is not significant, and migrant workers work skill levels influence is more significant. Within each industry, the new generation of migrant workers with low literacy levels are still only in the low-end, the lack of the technical content of the manual labor, and such work to assist the new generation of migrant workers to enhance their own little help. Their level of education and vocational skills level lags behind the needs of the urban labor market is a critical issue to hinder its long-term stability of employment in the city. It cannot be ignored, migrant workers in the process of into the city, for a citizenship and self-innovation, including changes in daily behavior, to participate in various training, cultural wealth accumulation, etc., their cultural qualities to get rid of the tradition-bound, while increasingly showing a tendency of urbanization. It is thus clear that, migrant workers only have a certain skill is not enough, you need to have a comprehensive quality and ability, including ideological and moral qualities, and cultural qualities, and political quality, legal awareness, the need for a comprehensive education for farmers. 


\subsection{The evolution of migrant worker's educational concept will improve the investment of their children and themselves gradually}

The educational state and conceptions of migrant workers will progress with the change of era and environment. Especially, the new-age peasant workers have strong potential educational demand, which will improve the investment of their children and themselves gradually.

Their experiences in cities cause them to know that the higher level of culture and culture has the superiority and personal qualities determine social status, employment selection and treatment. The survey of migrant workers also shows that more than half are willing to learn a new skill and they are willing to spend money in training. Various forms of training for rural migrant are taken to increase their momentum. At the same time, they also have their children received a good education by choosing a better school or urban school. Under investigation, when they were questioned by this question, do you have the plan to receive the educational training in the next few years, $52 \%$ of people said "yes". The future training willingness and diploma level are positive correlation significantly, namely the higher educational background, the more training willingness. With the improvement of educational level, the proportion of training people will go up continually. It is necessary for society, government and enterprises to provide training conditions and opportunities.

\subsection{The serious deficiencies of farmer education}

Farmer education can be divided into broad and narrow sense. The narrow sense aims at the education of practical skills, namely the farmer vocational education. The broad sense is integrated and systematic education, involving farmers' vocational education, moral education and life education, citizenship and legal education. Farmer education differs from that of the rural education and agricultural education. Rural education is kind of compulsory education, including the education of children of migrant workers. Agricultural vocational education aims to cultivate the agricultural professional skills. The agricultural section of extension plays a prominent role. Agricultural education, rural education and farmer education consists of an organic and integrated system in rural area. The famer education in this paper will mainly discuss the broad-sense level including farmers' vocational education. The serious deficiencies will be analyzed from the aspect of school education, vocational training and amateur cultural education.

The rural education is in dilemma. Present fundamental education is a system of grade school, which accustom to urban \& rural dualistic system and the whole society. So school-age children education problem of new-age peasant workers has become a blind management area. As we know that the stage of compulsory education funds is mainly borne by the local government. And the compulsory of the school-age children is in the charge of the local department because it is the place of registered permanent residence. So the public school of inflow area is not willing to accept the migrant children. There are few migrant workers who have ability to send their children to public schools. The majority migrant workers send their children to "migrant children schools" that is usually poor condition. Some of their children have to stay hometown or even drop out of the school. The educational quality of the left-behind children is quiet poor. Firstly, the number of children in the rural area decreases resulting in the cut and merger of some schools. So some remote-area students are difficult to go to school. Secondly, the left-behind school often separated from their parents causing the shortness of educational time and poor quality. Those children are difficult to form a right conception for learning and they have no ways to learn unworriedly, forming new gap between urban and rural areas.

At present, the vocational skill education of migrant farmers is beset with difficulties, which can be roughly classified into three types: (1)"green certificate", the vocational training in rural area implement by the Agriculture Department and its local bureaus; (2) peasant education carried out by China Agriculture Technology Extension System via technology promotion; (3) diploma education and non-diploma education in agricultural universities, colleges and secondary technical schools. These three types, implemented by different institutions but aiming at different achievements 
according to their own objectives, show a discordant development in the system of farmer education. Moreover, there are other issues worth mentioning:

- More government support is needed. Now the feedback of our farmer vocational education is not as instant and effective as other industries, which fails to attract enough attention of many local governments and relevant departments.

- The quality of vocational training of farmers needs to be improved. There are obvious gaps between teaching staff construction and the requirements of vocational education; curriculum needs to be redesigned to adapt itself to social development and students `actual needs; better teaching condition, more modern experimental apparatus, training equipment and practice bases.

- We need to broaden the investment channel for rural vocational education and optimize the distribution of educational resources. On the one hand, China's vocational and technical education, sponsored by government and run by relevant departments, lacks enough educational funds, which has long been a bottle-neck issue restricting the development of farmer education; on the other hand, migrant workers training is faced with a series of challenges - low income, high training cost, inflexible time, less systematic training content, few skills provided by training institutions, etc.

Our rural cultural construction needs to be eagerly improved. Since the reform and opening up, the standard of value of Chinese people has underwent tremendous changes_ — instead of paying attention to rural cultural construction, we were engrossed in how to improve our income. The rural culture begins to decay as the elite of farmers and young people gradually flow into city. On the one hand, government's lack of attention and investment causes the inadequate development of public service facilities. Having established many cultural stations and libraries in rural areas and implemented the project of "culture going to the countryside" in recent years, our country did not build enough pathways to directly introduce national policies, legal knowledge and work on moral education. In most cases, farmers obtain the information via television, network and magazine. On the other hand, failing to recognize of the importance of all-round education, farmers themselves also think little of the long-term interests that ideological and moral education, knowledge education, the learning of legal knowledge and citizenship education can bring to them. What they value more is economic benefit that technology can give, thus making it extremely difficult to create the atmosphere of developing farmer education.

\section{Solutions and suggestions}

\subsection{Central government balances urban and rural development by building up a compulsory education system for children of migrant workers}

As migrant workers continuously move from one place to another, any local government, source region or target region, finds it impossible to solve problems resulting from this migration movement on its own. So my suggestion is that we should, based on the current education system, build up a well-funded, fair and reasonable compulsory education system for children of settled and floating populations in urban and rural areas to make sure those children are not deprived of education because of poverty and enjoy a low-cost, high-level compulsory education without being discriminated. At the same time, more investment needs to be increased into rural schools. And we should put social benefit first and help left-behind children receive education easily after the merger of the schools.

At the same time, investment in schools in rural areas should be increased, social benefit should be put first to avoid the phenomenon of the difficulty the stay-at-home children face caused by the combination of schools.

\subsection{To build a multi-level, wide coverage, low profit entities and the network education with the combination of vocational education and skills training system}


In the professional training of migrant workers, the first problem should be solved is the training content which is or lag or disconnect with the actual work; the second is to pay attention to the bad effect of the training may be led to; The last but not lest is to overcome the tendency to record the achievements in the official career and the formulation in the training. Increasing investment in farmers' vocational education and training, and integrate the existing education and training resources. To set up the vocational education, which combine the physical education with the internet education to alleviate the problem of insufficient training time. It is convenient to use the Network Education in the theory teaching. Physical education for operating practice is good for grasping the actual operating point better. Nationwide, integrate the existing vocational schools and vocational training institutions, training bases through some effective way, to establish a national or a regional chain of vocational training group. One can improve the utilization rate of existing resources of society; Second, migrant workers can choose to attend all the project anytime and anywhere skills training, training expenses and personal contribution by the national social minimizing individual pay, training certificate of the national general, gradually establish a high labor skills of the labor force. Give full play to the role of the institutions of higher learning, offering academic education opportunities to work while in school, improve education level of migrant workers.

\subsection{Place more emphases on Farmers amateur cultural education}

In order to promote farmers' overall quality as much as possible, in addition to providing kinds of knowledge and skills training and a variety of learning opportunities for the migrant workers, their ability to survive in the city, including changes in daily behavior also must be improved. First of all, government and farmers should be fully aware of the role of amateur cultural education in thought; Second, new popular communication method should be introduced through the forms that farmers like best such as rural drama, novels, folk proverb and so on, using media such as network, television, newspaper, color leaflets, raising farmers' education effectiveness. Finally, based on all kinds of education in the countryside, we can carry out specialized infusion and guidance. Besides, we can cooperate with the social from all walks of life to introduce high quality team of experts to design some special topics that peasant farmers like to listen to and is easy to understand, to conduct all kinds of quality education, including the legal education, the civil morality education, health and hygiene education, home economics education, environmental education, cultural education, information education to make more farmers have the opportunity to become a citizen, it can also cultivate new farmers for the modern agriculture to realize the coordinated development of urban and rural areas.

\section{Acknowledgment}

The paper is sponsored by Soft Science Project of Shanxi Province: Shanxi rural social stratum differentiation in rural urbanization development question research — as a family as the stratified unit (2011041038-05).

\section{References}

1. DOU Xiaohong, Opportunity brought by the institution and the urbanization of farmer workers with new abilities, China Youth Study, pp.36-40, July 2006.

2. FAN Rong, The Influence of Migrant Workers' Generation Change on Process of Urbanization, Social Sciences Journal of Colleges of Shanxi, pp. 36-39, February 2010.

3. LIANG Hong, Migrating-out and Left-behind in the View of Life Course: A Comparative Analysis of the Characteristics of the Second - generation Migrant Workers, Population Research, pp.17-24, July 2011.

4. ZHOU Ying, A Comparative Study of Social Integration in Cities: The Youth and the Older Migrant Workers, China Youth Study, pp.54-58, March 2009. 
5. WANG Zongping, DUAN Chengrong, Analysis on the Characteristics of the second Generation Peasant - workers, Population Research, pp. 39-44, February 2010.

6. WANG Chunguang, A Social Sociological Analysis on Inclusion Process of New Generation of Migrant Workers, Journal of Youth Research,pp.5-15, March 2010.

7. LI Peilin, TIAN Feng, A Cross Generational Comparison of the Social Cohesion of Migrant Workers in China, Chinese Journal of Sociology, pp. 1-24, May 2012.

8. LI Peilin, TIAN Feng, The new generation of migrant workers: social attitudes and behavioral choices, Chinese Journal of Sociology, pp. 1-23, March 2011.

9. YANG Juhua, Misunderstandings for New Generation Migrants, Population Research, pp. 44-56, February 2010.

10. XU Chuanxin, CHEN Guohua, Analysis on Social Support in Education of Children of Migrants, China Youth Research, pp.25-32, September 2004.

11. XIONG Chunwen, The Life-world of Left-behind Children Based on Dad and Mum, Do You Know? Letters from Left-behind Children in Rural China, China Agricultural University Journal of Social Sciences Edition, pp. 101-107, January 2011.

12. CHEN Hui, XIONG Chunwen, On the Intergenerational Division of Migrant Workers: Based on Mannheim's Sociology of Generation. China Agricultural University Journal of Social Sciences Edition, pp. 51-63, April 2011. 